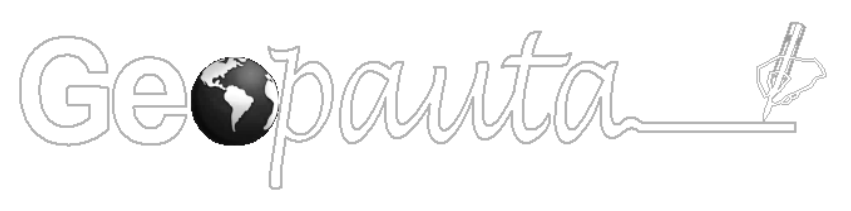

\title{
ESTRATÉGIAS DE REPRODUÇÃO E MANUTENÇÃO DOS EMPREENDIMENTOS SOLIDÁRIOS DO MUNICÍPIO DE SALGADO/SE
}

\section{Reproduction and maintenance strategies of solidarity enterprises in the municipality of}

\author{
Salgado / SE
}

\section{Estrategias de reproducción y mantenimiento de empresas solidarias en el municipio de Salgado / SE}

\author{
Daniela Santos Feitoza ${ }^{1}$ http://orcid.org/0000-0003-1330-5463 \\ José Eloízio da Costa ${ }^{2}$ http://orcid.org/0000-0002-3777-5403 \\ Fabiana dos Santos Pinheiro ${ }^{3}$ http://orcid.org/0000-0002-9508-6139
}

\footnotetext{
${ }^{1}$ Mestranda pela Universidade Federal de Sergipe- PPGEO/UFS - Brasil, email: danielafeitoza22@ gmail.com

${ }^{2}$ Doutor pela Universidade Estadual Paulisa - UNESP, - Brasil; Professor Titular do departamento de Geografia da Universidade Federal de Sergipe - UFS- Brasil, email: eloizio.npgeo@gmail.com.

${ }^{3}$ Graduação - Universidade Federal de Sergipe- UFS- Brasil. Email: Fabiana-Pinheiro16@ hotmail.com
}

\begin{abstract}
Resumo
Os princípios solidários na pequena produção demonstram importantes perspectivas para a construção de uma consciência coletiva entre os cooperados e a comunidade local. Sendo assim, esse artigo visa analisar o desenvolvimento e os principais reflexos da Economia Solidária para o fortalecimento da agricultura familiar do município de Salgado/SE. Destacando ainda o atual período de ortodoxia econômica (especialmente em nível nacional), marcado pela redução das políticas públicas de inclusão produtiva e da extensão das atividades solidárias. Diante dessas contradições, a Economia Solidária tem sido fundamental para garantir as estratégias de reprodução da pequena produção. Para tanto, é importante idealizar essa organização solidária para além de políticas públicas, visando destacar sua relevância na formação de uma sociedade justa, autônoma e menos desigual.
\end{abstract}

Palavras-chave: Economia Solidária. Espaço. Agricultura Familiar.

\begin{abstract}
The principles of solidarity in small production demonstrate important perspectives for the construction of a collective awareness between the members and the local community. Thus, this article aims to analyze the development and the main reflexes of the Solidarity Economy for the strengthening of family farming in the city of Salgado / SE. Also highlighting the current period of economic orthodoxy (especially at the national level), marked by the reduction of public policies for productive inclusion and the extension of solidarity activities. In the face of these contradictions, the Solidarity Economy has been instrumental in guaranteeing the reproduction and maintenance strategies of small production. Therefore, it is important to idealize this solidary organization beyond public policies, aiming to highlight its relevance in the formation of a just, autonomous and less unequal society.
\end{abstract}

Keywords: Solidarity Economy. Space. Family Farming. 
Daniela Santos FEITOZA, D. S.; COSTA, J. E. da; PINHEIRO, F. dos S.

\section{Resumen}

Los principios de solidaridad en la pequeña producción demuestran importantes perspectivas para la construcción de una conciencia colectiva entre los miembros y la comunidad local. Así, este artículo tiene como objetivo analizar el desarrollo y los principales reflejos de la Economía Solidaria para el fortalecimiento de la agricultura familiar en la ciudad de Salgado / SE. También destacando el período actual de ortodoxia económica (especialmente a nivel nacional), marcado por la reducción de las políticas públicas para la inclusión productiva y la extensión de las actividades de solidaridad. Ante estas contradicciones, la Economía Solidaria ha sido fundamental para garantizar las estrategias de reproducción y mantenimiento de la pequeña producción. Por lo tanto, es importante idealizar esta organización solidaria más allá de las políticas públicas, con el objetivo de resaltar su relevancia en la formación de una sociedad justa, autónoma y menos desigual.

Palabras clave: Economía Solidaria; Espacio; Agricultura Familiar;

Recebido em: 18/10/2019

Aceito para publicação em: 05/12/2019

\section{Introdução}

A Economia Solidária trata-se de um diferente formato de produção e comercialização, cujo caráter humano está no centro das coisas e tem o intuito de refletir sobre o atual modo de produção capitalista. Nesse aspecto, Singer (2002, p. 09) assevera que "a solidariedade na economia só pode se realizar se ela for organizada igualitariamente pelos que se associam para produzir, comercializar, consumir ou poupar". Vale dizer que ela surge no Brasil no período da redemocratização (década de 1980/90), graças aos esforços de inúmeras entidades ligadas à Igreja Católica, sindicatos, movimentos sociais e universidades (SINGER, 2002, p. 112). Esse período é marcado por uma grande euforia da tendência neoclássica que tinha o objetivo de impor as práticas liberalizantes de privatização e desregulamentação, sobretudo no mundo ocidental (CHESNAIS, 1996, p. 34). Por outro lado, o século XXI foi marcado pela mudança desse paradigma, o que fomentou a espacialização e territorialização desse estilo de produção, mediante arranjos institucionais cooperativos, sobretudo, nas regiões Sul e Nordeste.

No caso de Sergipe, essas atividades tem conquistado destaque especialmente na porção sul do estado, ajudando a fortalecer a produção de cooperativas e associações locais. Entretanto, desde o ano de 2016 a política pública que sustentava a espacialização da Economia Solidária em território nacional vem sofrendo redução drástica, refletindo sobremaneira no incentivo a produção e a circulação em âmbito 
Daniela Santos FEITOZA, D. S.; COSTA, J. E. da; PINHEIRO, F. dos S.

estadual e municipal. Apesar disso, os cooperados e associados buscam estratégias de reprodução para manter o funcionamento desses empreendimentos solidários. Sendo assim, é importante indagar como os princípios solidários têm ganhando espaço, se destacando na construção de processos coletivos que visam à promoção da autonomia desses produtores rurais? Dessa forma, é possível questionar ainda como e de que maneira a agricultura familiar do município de Salgado vem fazendo uso das atividades solidárias nos empreendimentos econômicos?

Nessa perspectiva, o presente artigo foi subdivido em cinco seções: a primeira, introdutória, que explica a temática abordada seus objetivos e a metodologia empregada; a segunda destinou-se a apresentar a trajetória de organização da fabriqueta de doces do povoado Tombo, em Salgado/SE; a parte subsequente foi proposta para expor o funcionamento das redes de cooperação solidárias locais e seus principais entraves; a quarta parte enfatiza as principais estratégias de reprodução social frente às contradições do período atual; e, finalmente, a última parte expõe as considerações finais.

Com isso, o objetivo geral deste artigo visa compreender de que maneira a Economia Solidária tem contribuído para o fortalecimento da reprodução social e a formação da renda dos agricultores familiares do município de Salgado/SE. Tendo como objetivos específicos: a investigação da trajetória de organização e institucionalização da fabriqueta de doces do povoado Tombo; análise do funcionamento das redes de cooperação entre os empreendimentos locais; discussão acerca das principais estratégias de reprodução social a partir da produção e comercialização solidária.

Os procedimentos metodológicos utilizados para alcançar os objetivos elencados foram à pesquisa bibliográfica, leitura e discussão de textos que conceituam Economia Solidária, agricultura familiar, redes, reprodução social, etc. Esses trabalhos foram analisados, discutidos e sistematizados através de fichamentos e resenhas. Para isso, as fontes de dados secundários (Governo de Sergipe, Instituto Brasileiro de Geografia e Estatística (IBGE), entre outros) foram imprescindíveis para a materialização desse trabalho.

A pesquisa empírica teve sua realização in loco, na fabriqueta de doces do município de Salgado, no dia 24/05/2019, onde houve a aplicação de questionário e entrevista semiestruturada, destinada as associadas desse empreendimento. Todavia, foi possível dialogar ainda com representantes da Cooperativa dos Produtores Agrícolas do 
Daniela Santos FEITOZA, D. S.; COSTA, J. E. da; PINHEIRO, F. dos S.

Sul de Sergipe (COOPATSUL), visando conhecer as interações sociais e espaciais dos demais empreendimentos locais. Nesse sentido, Marconi e Lakatos (2003, p. 188) apontam que "o caráter analítico e exploratório facilita a obtenção de descrições, tanto quantitativas quanto qualitativas do objeto de estudo, e o investigador deve conceituar as inter-relações entre as propriedades do fenômeno, fato ou ambiente observado". Por isso, essa coleta de dados e informações garantiu a sistematização das análises (teoria, empiria e dados) e de construção dos resultados evidenciados nesse trabalho. Já a estruturação dos dados (tabela, mapa, etc.) foi realizada no Word e Excel, via software Windows (2010), além do programa QGIS.

Esse trabalho justifica-se pela necessidade conhecer e compreender as relações de produção local a partir da Economia Solidária no referido município. Enfatizando ainda a importância das potencialidades desses espaços e da criação de alternativas que viabilizam a reprodução social, diante das contradições do contexto atual. Sendo assim, espera-se que esse breve ensaio possa auxiliar demais discussões acadêmicas sobre as realidades locais da Economia Solidária e agricultura familiar em Sergipe. Além de ser uma proposta de contribuição para o entendimento das redes de cooperação solidárias mediante organização e produção do espaço rural.

\section{Empreendimentos Econômicos Solidários no Município de Salgado/SE: o caso da Fabriqueta de Doces do Povoado Tombo}

O município de Salgado está localizado na porção centro sul do estado de Sergipe e corresponde a uma área de 247,579 quilômetros quadrados (mapa 01), sendo uma região predominantemente ocupada por pastagens e atividades agrícolas (SIQUEIRA/EMBRAPA, 2010, p. 82). Sua população absoluta é de 19.970 habitantes, onde cerca de 7,7\%, desse percentual total, são de pessoas que possuem algum tipo de ocupação formal (IBGE, 2018, p. 01). Isso demonstra o nível de dependência que a população do município tem sob as atividades no meio rural (geralmente não formalizadas). Sendo assim, essas características podem revelar um município marcado pelos aspectos rurais, no entanto, Abramovay (2000, p. 10) reitera ainda que "além de uma abordagem que enfatiza a relação com a natureza, às áreas não densamente povoadas e a dependência do sistema urbano, é importante abordar as ruralidades a partir da identificação de atividades mais sustentáveis para geração de renda”. 
Daniela Santos FEITOZA, D. S.; COSTA, J. E. da; PINHEIRO, F. dos S.

Mapa 1- Localização do Município de Salgado/SE.

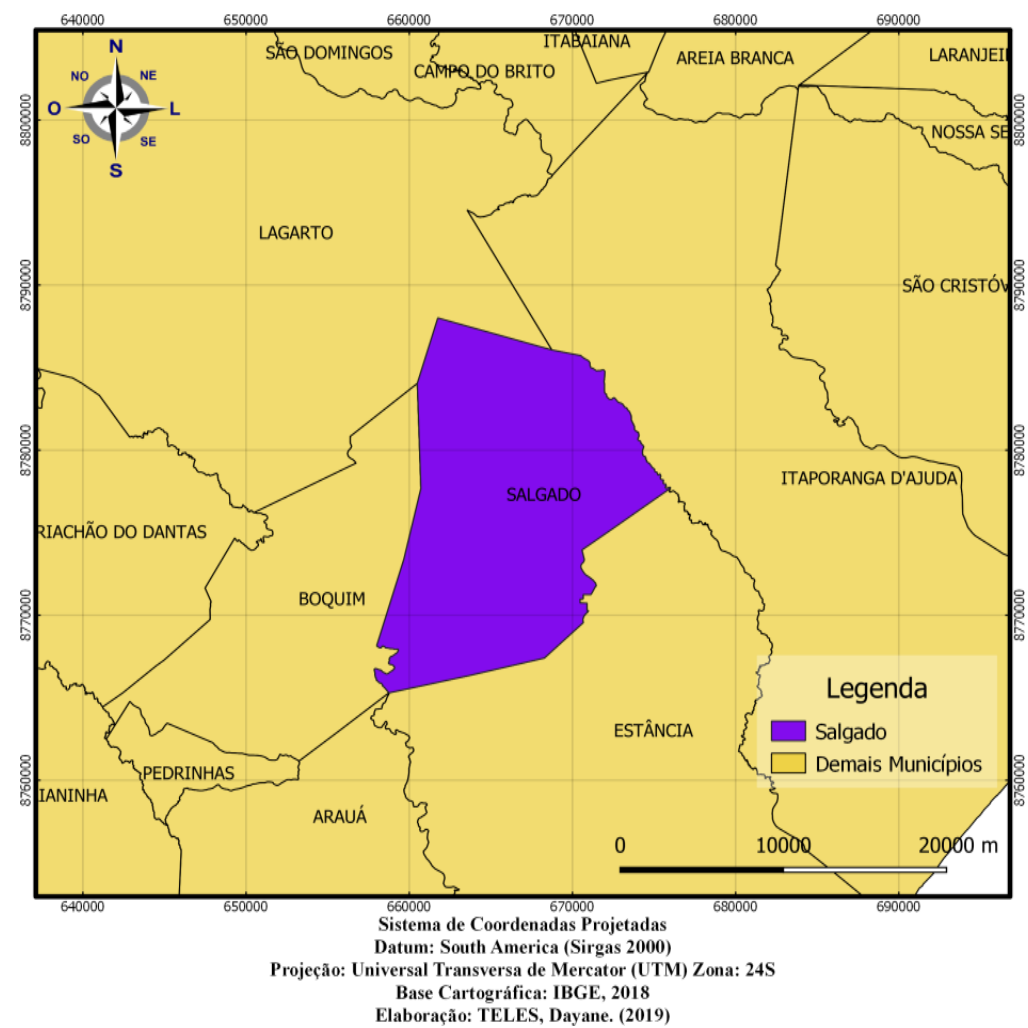

\section{Mapa de Localização \\ do Município de Salgado/SE}

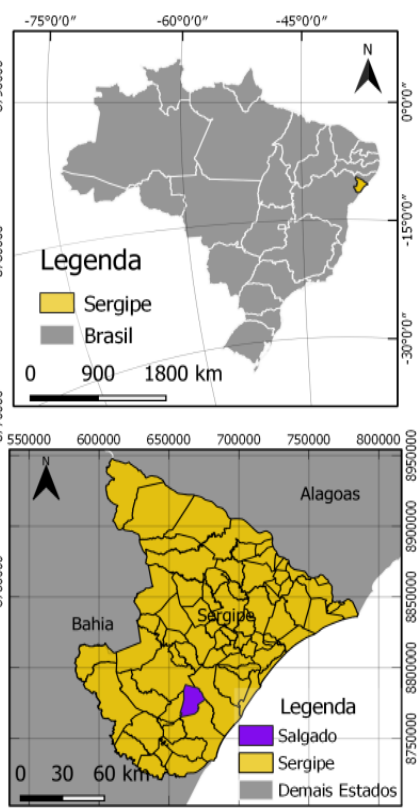

Fonte: IBGE (2018).

Sobre as características físicas, o município possui cerca de $85 \%$ do seu território sob o domínio do Grupo Barreiras (composto por areias finas e grossas com níveis argilosos a conglomeráticos), enquanto que seu caráter hídrico é favorecido pela presença do Rio Piauí, que faz a drenagem principal, além dos rios Piauitinga e Fundo (CPRM, 2002, p. 05) (mapa 1). Dessa forma, tanto o aspecto social quanto o físico favorecem a produção de lavouras permanentes (acerola, banana, caju, goiaba, graviola, laranja, limão, manga, mamão, maracujá, etc.) e temporárias (abacaxi, abóbora, amendoim, cana-de-açúcar, cebola, fava, feijão, fumo, mandioca, melancia, milho, sorgo, entre outros) na região.

Outra peculiaridade do município é a presença de cooperativas de agricultura familiar que possibilita compras em comum a preços menores e vendas em comum a preços maiores (SINGER, 2002, p. 89). Com isso, o maior destaque territorial é a Cooperativa dos Produtores Agrícolas do Sul de Sergipe (COOPATSUL), tratando-se de uma referência central de das práticas solidárias e de inclusão produtiva, pois exerce papel funcional de receber e escoar a produção dos agricultores familiares, assim como da fabriqueta e demais estabelecimentos do arranjo cooperativo local que não conseguem comercializar dignamente sua produção com demais grupos econômicos, a exemplo da Fabriqueta de doces do municipio de Salgado, que atualmente mantem suas 
Daniela Santos FEITOZA, D. S.; COSTA, J. E. da; PINHEIRO, F. dos S.

atividades em parceria com a Associação Comunitária dos Moradores do Povoado Tombo, localizada na zona rural.

Inaugurada em janeiro de 2014, essa fabriqueta é um dos 547 projetos comunitários realizados pela Empresa de Desenvolvimento Sustentável do Estado de Sergipe (PRONESE) que promove esses trabalhos desde 2012, com recursos do Projeto de Combate à Pobreza Rural (PROSPERAR), resultado do acordo de empréstimo entre o Banco Mundial e o Governo do Estado de Sergipe, fruto de um investimento de R\$ 83.400.000,00 (oitenta e três milhões e quatrocentos mil reais), cujo intuito é fomentar projetos comunitários de caráter produtivo e algumas infraestruturas regionais (GOVERNO DE SERGIPE, 2014, p. 01). O apoio institucional da PRONESE deu contribuição para incentivar a inclusão produtiva, o desenvolvimento local e o destaque das potencialidades regionais. Assim:

O Governo do Estado de Sergipe, através da Empresa de Desenvolvimento Sustentável de Sergipe (PRONESE), investiu no município de Salgado o valor de R\$ 3.404.189,00. Desse total de recursos aplicados, R \$ 1.095.238,64 foram originados do Projeto Prosperar, possibilitando a construção de nove sistemas de abastecimento de água, um trator com implementos, um centro de artesanato, dois projetos de recuperação de pomares e uma fábrica de doces e bolos recém inaugurada pelo governador Jackson Barreto. Todas as ações beneficiaram cerca de 777 famílias (GOVERNO DE SERGIPE, 2014. p. 01).

A ação das políticas públicas vem sendo sentidas no território sergipano, sobretudo a partir da década de 1960, com fins econômicos, haja vista a imposição de estruturas, conjunturas, padrões de sociabilidade e culturas incomuns a condição local (CARVALHO et al, 2019, p. 140). Por isso, a implantação desses projetos visa promover a redução das desigualdades territoriais. Essas diferenças espaciais são explicadas por Smith (1988, p. 212) como "resultado do movimento de vaivém do capital em direção à condição lucrativa que cada espaço pode proporcionar”. Portanto, é sabido que dentro das contradições da relação Estado-sociedade as políticas públicas ganharam destaque nos últimos anos, principalmente para a manutenção de projetos e programas sociais locais e regionais.

Todavia, com a disponibilidade dos recursos, a associação dos moradores do povoado Tombo realizou uma reunião com a comunidade para dialogar sobre as possíveis demandas para a construção do empreendimento solidário, onde foram disponibilizadas as opções de criação de uma creche, padaria ou uma fábrica de doces 
Daniela Santos FEITOZA, D. S.; COSTA, J. E. da; PINHEIRO, F. dos S.

(inicialmente de derivados da mandioca, já que a comunidade possui essa potencialidade) (ENTREVISTA, 2019). Sendo assim, em consenso, os moradores optaram pela constituição da fábrica por dois motivos: reaproveitamento da infraestrutura do antigo estabelecimento (Casa de Farinha do Povoado Tombo) e fortalecimento das atividades produtivas locais com a mandioca. Isso garantiu novas funcionalizações e formas espaciais ao território, sem necessariamente modificar os objetos geográficos preexistentes (SOUZA, 2016, p. 69).

Dessa maneira, segundo o Governo do Estado (2014, p. 01), a entrega da fábrica "beneficiou, diretamente, 62 famílias e a comunidade passou a contar com a produção de doces das frutas regionais, bolos e bolachas derivados da massa de macaxeira ou mandioca (beiju, pé-de-moleque e biscoitos), entre outros". Vale dizer que a COOPATSUL teve contribuição fundamental nesse processo, pois permitia escoar a produção da fabriqueta e, ao mesmo tempo, promovia processos formativos de fortalecimento dos princípios da Economia Solidária. Isso garantiu que as mulheres participassem de demais formações, junto ao Serviço Brasileiro de Apoio às Micro e Pequenas Empresas (SEBRAE) e a movimentos de Economia Solidária, agroecologia, etc., para conhecerem novas formas de manuseio dos produtos (adequando às exigências do Ministério da Saúde), buscando integrar inclusive os conhecimentos que elas já possuíam a partir de vivências na produção dos doces locais.

É importante enfatizar que no princípio a organização da fábrica contou com a participação de 45 mulheres, pois a presença feminina na produção de doces é culturalmente hegemônica no povoado. Porém, atualmente, somente 06 mulheres frequentam o estabelecimento ${ }^{4}$, por conta das dificuldades que foram surgindo nos últimos anos. O fator mais emblemático desse afastamento foi a retomada da política neoliberal que tem refletido no êxodo rural, pois diversas mulheres tiveram de migrar para demais regiões em busca de emprego e novas formas de reprodução social (tabela 01). Destarte, as mulheres que ainda resistem vêm se esforçando para manter a dinâmica das atividades do empreendimento e gerar o máximo de renda possível para apoiar a comunidade. Vale dizer que essas associadas tem consciência (adquiridas nos processos de formação da Economia Solidária) de que se as atividades produtivas não se mantiverem a comunidade também sofrerá consequências.

\footnotetext{
${ }^{4}$ Sendo que uma delas está afastada por questões de saúde. 
Daniela Santos FEITOZA, D. S.; COSTA, J. E. da; PINHEIRO, F. dos S.

Tabela 1- Perfil socioeconômico das associadas da fábrica de doces do povoado TomboSalgado-SE

\begin{tabular}{c|c|c|c}
\hline Entrevistadas & Id ade & Escolarid ade & Atividade exercida \\
\hline 1 & 55 & Fundamental (completo) & Doceira/Cozinheira \\
\hline 2 & 37 & Fundamental (incompleto) & Doceira \\
\hline 3 & 45 & Fundamental (incompleto) & Doceira \\
\hline 4 & 44 & Fundamental (incompleto) & Doceira \\
\hline 5 & 38 & Superior (completo) & Doceira/Vice-Tesoureira \\
\hline
\end{tabular}

Fonte: Pesquisa de campo aplicação de Questionario Fevereiro (2019).

O perfil socioeconômico das entrevistas caracteriza um ambiente de poucas oportunidades e de acesso aos serviços básicos de reprodução social, como educação. Sendo assim, Vasconcelos (2007, p. 222) salienta que "além da diversidade de experiências laborais, a exigência de qualificação do mercado tem marcado a luta pela sobrevivência nesses espaços solidários”. Por isso, apenas uma das associadas chegou a concluir o ensino superior (em Serviço Social), sendo esta que atualmente responde legalmente pelo funcionamento da fábrica. Além disso, esta associada é a única que participa do movimento de Economia Solidária em Sergipe, enquanto que as demais estão envolvidas com a atuação sociopolítica no Sindicato de Trabalhadores Rurais e no Movimento de Agricultores Familiares do Município de Salgado.

Isso infere no nível de organização social e na construção de uma consciência de valorização das relações de trabalho evidenciadas, sobretudo, no meio rural. Por isso Godoy (2009, p. 95) salienta ser importante "compreender como essas relações de trabalho tem sido decompostas pela propriedade privada, cedendo o espaço do trabalho coletivo para o trabalho individual, por isso a tarefa social de cada indivíduo condiz no reconhecimento de seu lugar no espaço, o que impulsiona no entendimento da luta de classes".

Vale apontar ainda que, para manterem-se na fabriqueta essas mulheres desenvolvem estratégias de reprodução e manutenção do empreendimento, como atividades extras para geração de renda coletiva em trabalhos informais de limpeza (faxina, diarista, etc.), revenda de produtos (cosméticos), trabalhos no campo, além da renda fixa advinda do Programa Bolsa Família, entre outras possibilidades (ENTREVISTA, 2019). Mesmo diante do nível de precarização do trabalho, isso reflete 
Daniela Santos FEITOZA, D. S.; COSTA, J. E. da; PINHEIRO, F. dos S.

de certa maneira na possibilidade de manterem-se na fabriqueta frente às contradições do período atual (painel 1).

Painel 1- Produção de queijadinha e pé-de-moleque na fábrica de doces de Salgado/SE
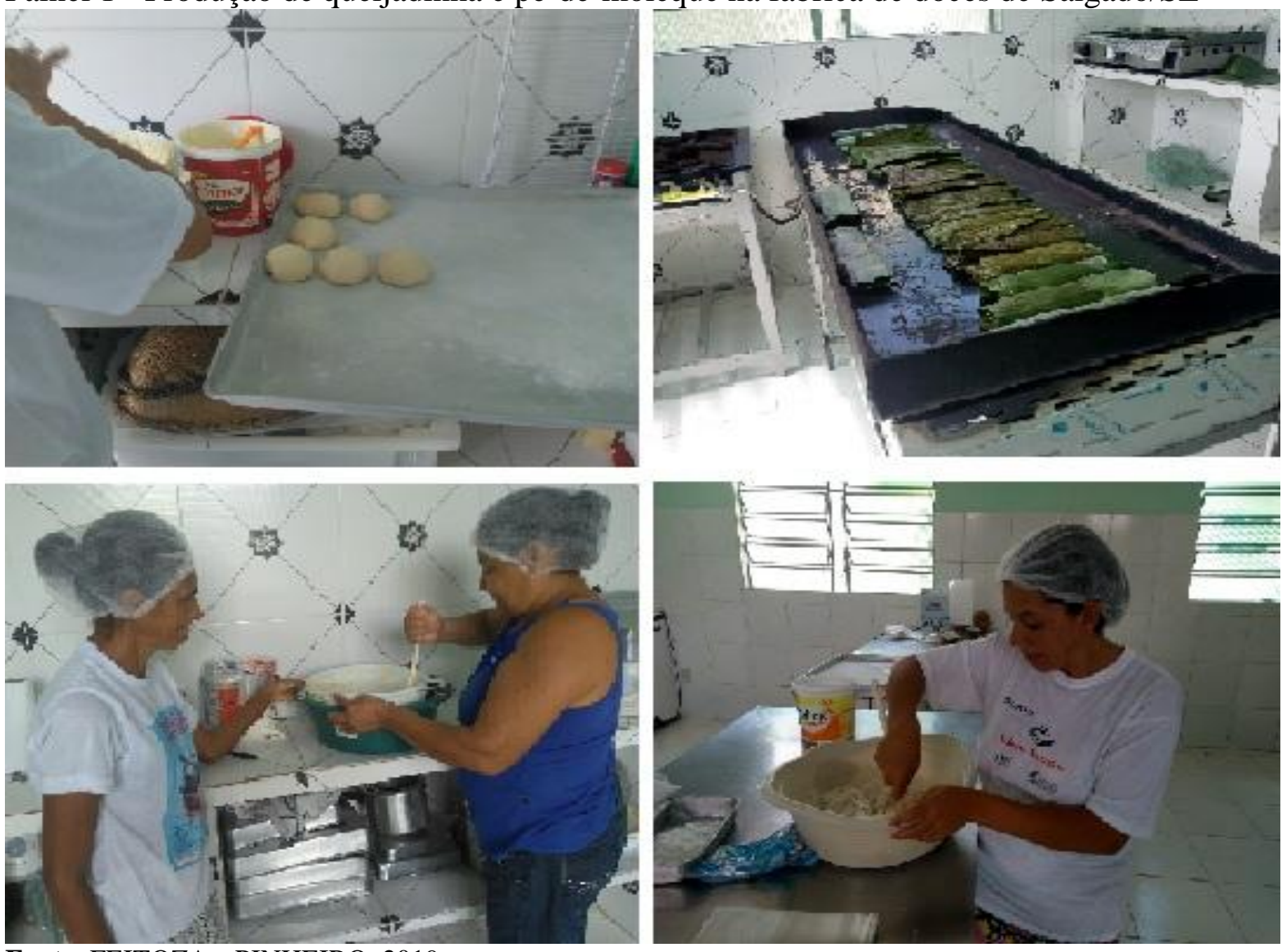

Fonte: FEITOZA e PINHEIRO, 2019.

Apesar da redução das encomendas, as mulheres ainda trabalham na produção de pé-de-moleque, queijadinha, cocada, beiju, bolos, bolachas e alguns pães (figura 01). Além disso, a maior parte dessa produção é destinada a Cooperativa dos Produtores Agrícolas do Sul de Sergipe (COOPATSUL) e outra parte são enviadas para a Prefeitura Municipal de Salgado, que adquire os produtos via Programa de Aquisição de Alimentos (PAA). Dessa maneira, as mulheres também buscam comercializar seus produtos, quando podem, em feiras públicas, eventos acadêmicos e de agroecologia. Com isso, a renda adquirida pela produção é viabilizada para a manutenção da fábrica (pagar contas de água, energia, gás, fornecedores, comprar produtos de limpeza e reabastecer o empreendimento) e outra parte é distribuída entre as associadas.

Assim, mesmo com os crescentes desafios na produção e circulação dos produtos da fabriqueta de doces, este empreendimento tem grande importância para o desenvolvimento local do povoado Tombo. Garantindo a reprodução social de inúmeras famílias rurais e mantendo as atividades produtivas da comunidade. Por isso, as 
Daniela Santos FEITOZA, D. S.; COSTA, J. E. da; PINHEIRO, F. dos S.

políticas públicas são basilares para manter e ampliar os processos solidários e de reprodução desses espaços.

\section{Redes de cooperação e seus principais entraves}

A Economia Solidária possui uma contígua relação com a agricultura familiar. Essa afinidade refere-se ao fato de que ambas valorizam a pequena produção, as relações niveladas de trabalho, as maneiras de se produzir e consumir, as formas de circulação, entre outros atributos. Nesse sentido, Schneider (2003, p. 100) aponta que "a agricultura familiar é uma categoria social que foi reconhecida recentemente no Brasil como uma demanda, sobretudo, do sindicalismo rural". Por isso, em meio às contradições do atual contexto neoliberal, essencialmente a agricultura familiar mostrase como uma estratégia de reprodução social frente a uma organização historicamente desigual.

Dessa maneira, as relações solidárias promovem o fortalecimento da agricultura familiar através do desenvolvimento de práticas coletivas no espaço rural, mediante atividades produtivas. Essas relações se revelam através das redes geográficas, que Corrêa (2012, p. 200) afirma serem "redes sociais (elaboradas no âmbito de relações sociais de toda ordem, envolvendo poder e cooperação, além daquelas de outras esferas da vida) espacializadas". De modo dinâmico, as redes geográficas conectam pessoas, objetos, atividades, etc. Assim:

A rede em tela está, de fato, espacializada, mas nem sempre a consideramos sob esse ângulo. A passagem de uma rede social para uma rede geográfica se dá quando assim a consideramos, a despeito de sua necessária espacialidade, expressa em localizações qualificadas, e com interações espaciais entre elas. É essa rede geográfica que interessa ao geógrafo. É a partir da problemática construída sobre uma dada rede que será selecionada os aspectos a serem estudados. (CORRÊA, 2012, p. 201).

Nesse sentido, tomando o espaço geográfico como um conjunto indissociável de sistemas de objetos e sistemas de ações (SANTOS, 1997), a rede pode ser compreendida como um sistema verticalmente orientado pela e para a ação/intenção de determinados agentes, para a coordenação do trabalho que flui entre pontos específicos no território. Podemos compreender como se estruturam as suas políticas de articulação no território. Dentro delas, novas oportunidades são criadas o tempo todo. Fora das redes, a sobrevivência fica cada vez mais difícil. 
Daniela Santos FEITOZA, D. S.; COSTA, J. E. da; PINHEIRO, F. dos S.

Para isso, deve-se ficar atento aos benefícios da organização em forma de redes, tais como: capacidade de inserção social de grupos, democratização dos saberes e a agilidade em alguns processos de produção e de trabalho (ORTIGOZA, 2015, p. 09). Portanto, o relacionamento da COOPATSUL com os demais estabelecimentos solidários da cidade de Salgado demonstra sua relevância territorial e relevância no aspecto regional, pois viabiliza e preferencia a produção e a comercialização local advindas dos pequenos produtores, principalmente da Fabriqueta. Isso evidencia uma lógica espacial solidária entre os empreendimentos, ocorrendo de maneira coletiva e mútua.

Apesar disso, as demandas pela produção solidária vêm sendo reduzidas significativamente, sobretudo, pela retomada da tese liberal na economia brasileira, marcando a redução dos investimentos públicos nas áreas sociais, especialmente em programas de incentivo a inclusão produtiva (PAA, PNAE, PRONAF, etc.) e influenciando ainda no fomento das disparidades socioeconômicas e regionais. Isso tem estrangulado a circulação dos produtos advindos da pequena produção e estagnado produções locais, além de enfraquecer o consumo alternativo. Portanto, com a queda de produção da fabriqueta de doces do povoado Tombo, as mulheres se veem em situações desconfortáveis por conta da redução marcante das encomendas, o que inviabiliza inclusive realizar certos pedidos por conta dos autos custos.

Essa situação apresenta-se como um dos maiores entraves para fortalecer as redes de cooperação no município de Salgado.

Atualmente, nosso maior problema é a venda. Pode mandar pra cá que a gente produz, mas na hora de vender é terrível. É que o pessoal acha caro, sendo que temos que colocar um valor em cima de cada produto e de cada dia de trabalho. É fácil dizer que tá caro, mas vamos vê quanto tá o valor do coco, macaxeira, ovos, etc.(INFORMAÇÃO VERBAL).

Diante disso, outra conjuntura que vem despertando um dos maiores e mais antigos problemas da organização solidária é o constante afastamento das associadas. Refletindo num verdadeiro processo de desmobilização dessas mulheres, além de desvalorizar e enfraquecer os processos coletivos que vinham sendo construído ao longo dos últimos anos. Por isso, esse distanciamento agrava ainda mais a produção local, por

\footnotetext{
${ }^{5}$ Entrevista realizada com associadas da minifábrica de doces do povoado do Tombo-Salgado/SE. Entrevista gravada por aparelho G4 (áudio $30 \mathrm{~min}$ ) em 30 de maio de 2019. Entrevista realizada por Feitoza, maio de 2019.
} 
Daniela Santos FEITOZA, D. S.; COSTA, J. E. da; PINHEIRO, F. dos S.

conta da necessidade de buscar renda alternativa noutros lugares, especialmente nos centros urbanos, como na cidade de Salgado e Aracaju.

Esse fenômeno representa ainda um dos maiores gargalos para a continuidade dos processos produtivos solidários, pois o trabalho realizado nessa fabriqueta depende muito do relacionamento com a associação dos moradores do povoado Tombo, especialmente no que se refere à manutenção do empreendimento. Sendo assim, a migração dessas mulheres representa, acima de tudo, o reajustamento de contas para as que ainda resistem. Embora com uma produtividade mínima, mas não insignificante essas mudanças refletem sobremaneira no cotidiano das famílias rurais, que dependem do que produzem para garantir sua reprodução diária.

Por conta disso, a comunidade sente-se desmotivada e enxerga tanto a associação quanto à fabriqueta como uma mera entidade de apoio a grupos específicos, desafetuando-se de toda a relação coletiva construída ao longo dos últimos anos, onde o afastamento é naturalmente encarado por todos. Dessa forma, as percepções de risco aliam-se diretamente a um quadro de emoções proveniente do afeto sentido pelos sujeitos em relação ao espaço (MONTEIRO e MONTEZ, 2015, p. 224).

Nessa perspectiva, o apoio institucional, mediante políticas públicas, é fundamental para potencializar os trabalhos de Economia Solidária, especialmente a produção. Por isso, entender o percurso do Estado através da história e das teorias políticas parece inevitável para analisar as políticas públicas de desenvolvimento socioeconômico, implementadas pelos governos brasileiros nas últimas décadas, e mais especificamente, as que tratam da Economia Solidária (GODOY, 2009, p. 114).

Apesar de reconhecer que o Estado é um agente econômico do capital, contraditoriamente, sua função também reverbera no desenvolvimento local, pois historicamente a reprodução social da periferia depende em grande medida das políticas públicas e nega-las dessa função social significa negligenciar as demandas da pequena produção. "A possibilidade de continuidade dos trabalhos sem o apoio das políticas públicas é muito difícil, porque a nossa maior dificuldade é a venda dos produtos já que são muito perecíveis, com apenas três dias de validade" (INFORMAÇÃO VERBAL, $2019)^{6}$.

No entanto, o que diferencia a Economia Solidária das demais políticas públicas é a possibilidade de se construir, coletivamente, processos de autonomia social futuros.

\footnotetext{
${ }^{6}$ Entrevista 2 realizada com associadas da minifábrica de doces do povoado do Tombo-Salgado/SE. Entrevista gravada por aparelho G4 (áudio $10 \mathrm{~min}$ ) em 30 de maio de 2019. Entrevista realizada por Feitoza, maio de 2019.
} 
Daniela Santos FEITOZA, D. S.; COSTA, J. E. da; PINHEIRO, F. dos S.

Nessa concepção é possível criar um novo ser humano a partir de um meio social em que cooperação e solidariedade não apenas serão possíveis entre todos os seus membros, mas sim formas racionais de comportamento, em função de regras de convívio que produzem e reproduzem a igualdade de direitos e de poder de decisão e a partilha geral de perdas e ganhos da comunidade entre todos os seus membros (SINGER, 2003, p. 116).

Outra problemática que acentua os gargalos para o fortalecimento das redes de cooperação está na comercialização, pois o escoamento de produção da fabriqueta depende de seus recursos próprios, embora em alguns casos a COOPATSUL realize o transporte de alguns produtos. Nesse aspecto, Marx (2005, p. 151) enfatiza que "a circulação é o processo de equivalência socialmente válido, sendo basilar para agregar valor à mercadoria". Porém, na maioria das vezes essas fabriquetas não têm recursos e/ou condições logísticas para manterem a circulação de suas mercadorias, estrangulando a comercialização e enfraquecendo a integração da produção solidária em todo o território.

Além das dificuldades com a circulação as associadas ainda encaram desafios na manutenção infraestrutural do prédio onde trabalham, dificultando inclusive na localização espacial do empreendimento. É que desde a sua entrega, a instituição solidária nunca passou por uma reforma de fato, por isso, as mulheres em coletivo com a comunidade tentam manter a infraestrutura da melhor forma possível, embora seja evidente a necessidade de melhorias e reformas, sobretudo na entrada (foto 1).

Foto 1 - Dianteira da Fábrica de Doces do município de Salgado/SE.

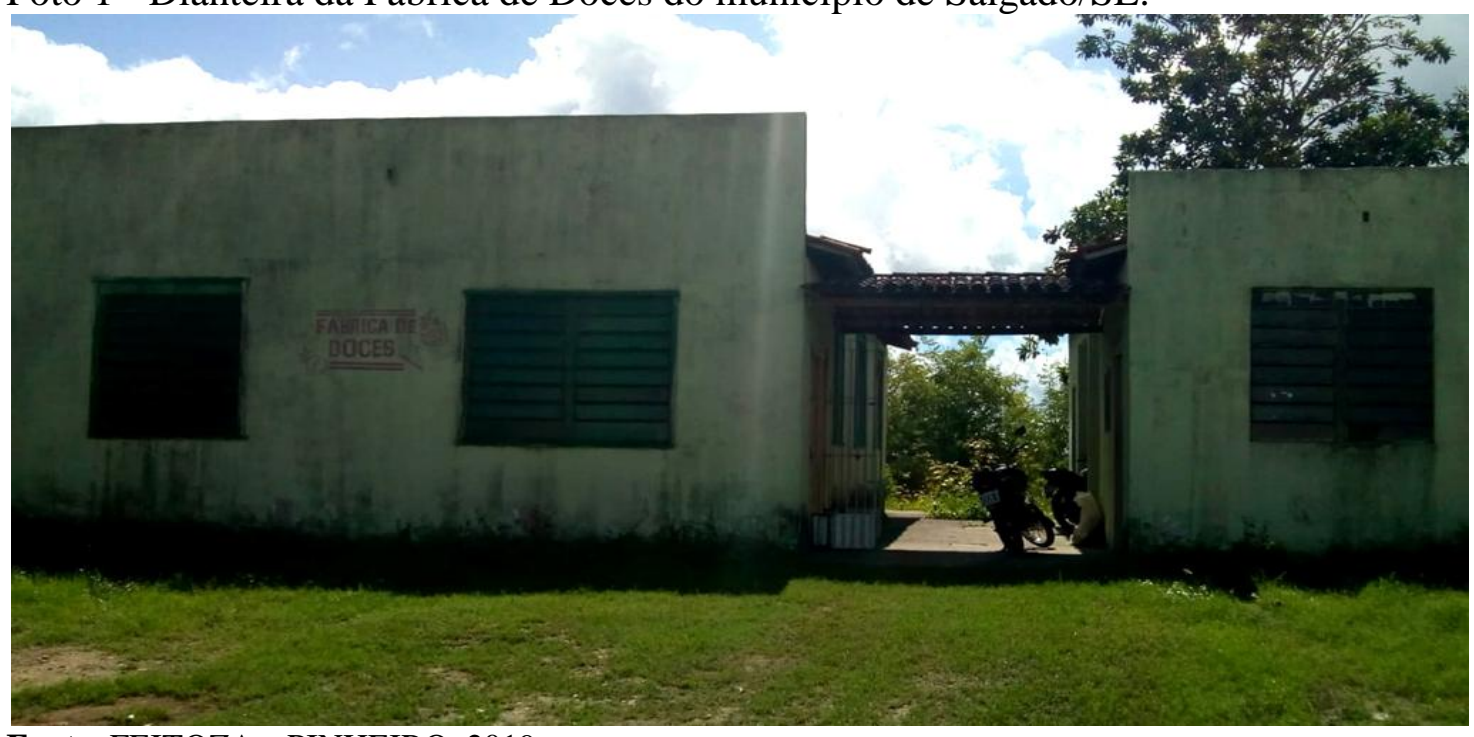

Fonte: FEITOZA e PINHEIRO, 2019. 
Daniela Santos FEITOZA, D. S.; COSTA, J. E. da; PINHEIRO, F. dos S.

Evidentemente, a infraestrutura externa do espaço está fortemente sucateada e nem a associação dos moradores muito menos a renda da fábrica, podem custear uma reforma de todo o empreendimento. Nesse caso, a própria comunidade costuma realizar, quando possível, os reparos com moradores que possuem alguma experiência com construção civil (pintura, hidráulica, elétrica, etc.) (foto 1). Dessa maneira, o apoio institucional deve viabilizar condições de manutenção periódica para assegurar as atividades do empreendimento, no entanto isso não tem ocorrido.

Esses entraves refletem, sobretudo, nos custos de produção de cada mercadoria, o que impossibilita fortalecer e expandir os trabalhos solidários. Todavia, os empreendimentos solidários do município de Salgado têm encarado seus maiores desafios nos últimos tempos com a queda do consumo e da produção, aumento dos preços, negligencia do Estado, entre outros. Isso tem influenciado nos processos de fortalecimento das redes de cooperação e descontruído uma tarefa tão fundamental para as economias locais: 'os trabalhos solidários'. Assim, a retomada desses processos será custosa, tanto para as políticas públicas quanto para a comunidade, por isso é essencial que a Economia Solidária seja encarada como uma ferramenta continuada de desenvolvimento local coletivo.

\section{Estratégias de reprodução e produção local}

A perspectiva neoliberal que tem ganhado aderência nos últimos anos, pelos governos brasileiros, impacta fortemente a condição econômica do país, assim como as políticas públicas de inclusão produtiva e social. Essa situação vem se agravando cada vez mais com a redução ininterrupta do consumo, especialmente das famílias de menor renda. Em nível nacional, as séries anuais a preços correntes demonstram um recuo significativo do PIB a partir de 2016. Tanto que a taxa de variação acumulada apresentou em dezembro de 2018 a razão de 1,1\%, marcando um dos maiores períodos de estagnação da economia brasileira recente (IBRE/FGV, 2019, p. 01). Por sua vez, esse percentual parece ser insignificante, mas se considerar a dinâmica econômica do Brasil nas últimas décadas, há de ser visto com preocupação.

A queda de investimentos públicos e de produção tem se moldado qualitativamente e, com isso, refletido na redução do consumo real. Todavia, Guerra et al (2017, p. 189) enfatiza que “essa condição se acentuará por conta da equivocada proposta de limite do crescimento dos gastos primários, corrigidos somente pelo Índice Nacional de Preços ao Consumidor Amplo (IPCA), durante 20 anos”. Nesse sentido, as 
Daniela Santos FEITOZA, D. S.; COSTA, J. E. da; PINHEIRO, F. dos S.

regras ortodoxas de controle dos investimentos, institucionalizadas em 2016 via Proposta de Emenda à Constituição n 55 (conhecida como PEC do Teto dos Gastos) tem refletido no desenvolvimento econômico e social do país, pois inviabiliza a redução das desigualdades diversas, que via de regra, necessita de recursos públicos.

Esse instrumento institucional legitimou o estrangulamento da economia e a destruição das políticas públicas, que visavam responder demandas, principalmente dos setores marginalizados da sociedade, considerados como vulneráveis, cujas diligências são interpretadas por aqueles que ocupam o poder, mas influenciadas por uma agenda que se cria na sociedade civil através da pressão e mobilização social (TEIXEIRA, 2002, p. 03). Dessa forma, sem o apoio e suporte financeiro as assimetrias sociais e econômicas serão cada vez mais evidenciadas. Com isso:

O Programa de Aquisição de Alimentos (PAA), considerada umas das principais políticas públicas de fortalecimento da agricultura familiar e de enfrentamento da fome e da pobreza no Brasil, sofreu um corte de $40 \%$ no orçamento de 2016, afetando milhares de famílias agricultoras. A redução de $\mathrm{R} \$ 478$ milhões para $\mathrm{R} \$ 294$ milhões diminuiu também o número de pessoas atendidas que passou de 91,7 mil para 41,3 mil, o que significa uma redução de $55 \%$ das famílias atendidas (IHU/UNISINOS, 2017, p. 1).

A redução dos investimentos para aquisição de alimentos da pequena produção reflete num verdadeiro desmonte da agricultura familiar. Nos municípios nordestinos, isso vem sendo cada vez mais significativo e influenciando, negativamente, nos processos de fortalecimento da inclusão produtiva. Tanto que os empreendimentos solidários da cidade de Salgado/SE já sofrem com a queda brusca da demanda local, todavia, buscam condicionar mudanças organizacionais para continuar e manter os trabalhos com Economia Solidária. No caso da COOPATSUL, as modificações vêm sendo inseridas nas parcerias comerciais (procura de novos fornecedores), aspecto logístico (terceirizando transportadoras), tipos de consumidores (em demais munícipios sergipanos e do norte da Bahia), formas de produção (revender novos produtos), entre outros mecanismos (ENTREVISTA, 2019).

Embora, essas mudanças internas sejam favoráveis para o sistema de cooperações, a COOPATSUL tem sido obrigada reduzir a obtenção dos produtos dos demais empreendimentos solidários e das fabriquetas por conta da baixa procura de suas mercadorias. $\mathrm{O}$ que infere na necessidade de transformações internas também por parte dessas instituições menores. Sendo assim, essas estratégias solidárias não competitivas 
Daniela Santos FEITOZA, D. S.; COSTA, J. E. da; PINHEIRO, F. dos S.

fazem diferenças significativas para reduzir os custos e manter o funcionamento dos empreendimentos e a reprodução social de inúmeras famílias rurais.

No caso da fabriqueta de doces do povoado Tombo, algumas ações coletivas já vinham sendo desenvolvidas e outras tiveram de ser incorporadas com o passar dos anos. Uma dessas mudanças tem sido a busca prioritária por matérias-primas (macaxeira, batata, coco, entre outros) na própria comunidade, condição que muitas vezes não ocorria, por conta dos preços e da variedade de produtos. Por sua vez, trata-se de uma ação baseada num processo de constante negociação e coletividade, para que ambos os lados não saiam perdendo.

Outra estratégia para aumentar a circulação e o consumo da produção solidária foi a busca por espaços alternativos de comercialização. Com isso, além da produção para a COOPATSUL (sendo alguns produtos exclusivos para este empreendimento) e da comercialização para a prefeitura (quando há pedido para serem distribuídos em escolas, creches, hospitais e demais instituições), a mini fábrica tem levados seus produtos para a Feira de Agricultura Familiar, que ocorre todos os dias de sábado. É importante frisar que essa feira abre espaço desde 2015 para a comercialização dos produtos da Economia Solidária no município. Assim:

As Feiras da Agricultura Familiar são um projeto do Governo de Sergipe, executado pela Secretaria de Estado da Mulher, Inclusão, Assistência Social, do Trabalho e dos Direitos Humanos - SEIDH, em parceria com o Ministério do Desenvolvimento Agrário - MDA, para fortalecer a agricultura familiar, criando frentes de comercialização para o escoamento da produção desses pequenos produtores rurais (GOVERNO DE SERGIPE, 2015, p. 1).

Esses ambientes são benéficos para o desenvolvimento local e para fortalecer as potencialidades regionais, que muito embora não seja valorizada pelo público em geral, pois não tem conhecimento dos processos de produção e das relações de trabalho, além de sua relevância para o consumo consciente e sustentável. Inclusive no diálogo, face-aface, com o consumidor. A proximidade geográfica possibilita as interações cognitivas, na medida em que se inscreve em um contexto organizacional e institucional adaptado (TORRE, 2003, p. 35).

Todavia, nesses espaços é possível dialogar ainda sobre questões ambientais e da saúde, como o debate sobre os níveis de agrotóxicos contidos na produção de larga escala que vem afetando, sobremaneira, a saúde de forma geral. Sendo esse um dos embates mais contundentes travados pela Economia Solidária, que está alicerçado na 
Daniela Santos FEITOZA, D. S.; COSTA, J. E. da; PINHEIRO, F. dos S.

'Campanha Permanente Contra Agrotóxicos e pela Vida', liderada por 30 entidades da sociedade civil brasileira (movimentos sociais, entidades ambientalistas, estudantes, organizações ligadas à área da saúde e grupos de pesquisadores), buscando denunciar o uso desses venenos e conscientizar sobre a relevância da produção saudável (CIRANDAS, 2011, p. 1).

Outra possibilidade da exposição dessa produção é a ampliação do marketing e, para isso, a mulheres da fabriqueta de doces do povoado Tombo tem realizado parcerias com a COOPATSUL para a utilização de etiquetas com logomarcas específicas e padronizadas. Desse modo, as ações têm viabilizados resultados consideráveis, tanto que apesar das dificuldades a fábrica tem sido procurada para realizar encomendas fixas, inclusive de revendedores da cidade de Aracaju, que geralmente fazem pedidos nos dias de sexta-feira (ENTREVISTA, 2019).

Vale dizer ainda que esses pedidos aumentam, consideravelmente, nos meses de maio e junho (temporada de festas juninas). "A expectativa é que, esse ano, tenhamos os mesmos pedidos do ano passado, com encomendas de, ao ou menos, 3.000 pés-demoleque, 200 quilos de bolo e 3.000 pãezinhos de macaxeira" (INFORMAÇÃO VERBAL, 2019) ${ }^{7}$.

Apesar da importância desse aumento de produção, as ações são temporárias, por isso, as mulheres buscam reservar uma parte daquilo que foi adquirido (excedente) para serem utilizados no custeio de contas nos demais meses do ano. Assim, conforme assinala Grisa e Schneider (2014, p. 139) “essas iniciativas, condicionadas por governos estaduais e municipais, criam seus próprios mecanismos de compras públicas e têm estimulado as organizações da agricultura familiar a demandarem e construírem novos mercados públicos e privados".

Dessa forma, por mais que pareçam ações isoladas ou até mesmo pouco significativas, essas estratégias têm contribuído para a manutenção dos empreendimentos solidários, assim como na renda de inúmeras famílias rurais. Desse modo, mesmo com todas as dificuldades, as mulheres têm desenvolvido meios alternativos de reprodução social. Com isso, é evidente que os processos de Economia Solidária qualificam essas relações de solidariedade, autonomia e democracia, sustentando ações de resistência, tão fundamentais para as perspectivas locais. Para

\footnotetext{
${ }^{7}$ Entrevista 3, realizada com associadas da minifábrica de doces do povoado do Tombo-Salgado/SE. Entrevista gravada por aparelho G4 (áudio $30 \mathrm{~min}$ ) em 30 de maio de 2019. Entrevista realizada por Feitoza, maio de 2019.

V. 3, n.03, 2019 http://periodicos2.uesb.br/index.php/geo

Este é um artigo de acesso aberto sob a licença Creative Commons da CC BY
} 
tanto, é essencial fomentar a Economia Solidária e amplia-la nos territórios e nos espaços rurais.

\section{Considerações finais}

Esse artigo apresentou uma discussão sobre a lógica de funcionamento dos empreendimentos solidários do município de Salgado, dando ênfase a fabriqueta de doces do povoado Tombo e o seu relacionamento interacional com a Cooperativa dos Produtores Agrícolas do Sul de Sergipe (COOPATSUL). Diante disso, foram realizadas investigações acerca da origem desses empreendimentos e de como eles contribuem para o desenvolvimento local. Vale dizer que as políticas públicas e o apoio do Estado são basilares para fortalecer os processos de Economia Solidária no território, assim como ampliar a produção e o consumo local dessas comunidades.

Dessa forma, a investigação buscou mostrar como a ausência do Estado, via políticas sociais e de inclusão produtiva, enfraquece os processos e amplifica as disparidades sociais, econômicas e regionais. Isso vem sendo bastante significativo com a retomada da perspectiva neoliberal no Brasil, sobretudo a partir de 2016, com a redução dos investimentos públicos nas áreas sociais e de transferência de renda. É importante frisar que essa questão não se trata de assistencialismo, mas do destaque histórico do Estado social, dentro das suas contradições, na redução das assimetrias socioeconômicas.

No entanto, em meio às contradições do período atual e com os reflexos dos trabalhos solidários, esses empreendimentos tem buscado desenvolver estratégias para manter seu funcionamento e favorecer a reprodução social dos cooperados e da comunidade. Evidentemente, as alternativas repercutem minimamente no desenvolvimento local e esses processos de autonomia e solidariedade já mostram resultados consideráveis, tanto na produção quanto na circulação.

Por sua vez, a questão fundamental que prevalece é da necessidade institucional para a continuidade e fortalecimento dos processos solidários, já que essencialmente a Economia Solidária está voltada para a organização do trabalho e dos trabalhadores nas comunidades e espaços mais pobres. Isso evidencia a representação e importância de uma política de inclusão de pessoas, geralmente de menor escolaridade e que não tiveram acesso às demandas do mercado, ao passo que necessariamente iria promover outro desenvolvimento dentro de uma nova possibilidade econômica. 
Daniela Santos FEITOZA, D. S.; COSTA, J. E. da; PINHEIRO, F. dos S.

Para tanto, é relevante valorizar o papel da Economia Solidária nos ambientes locais, pois o capitalismo cada vez mais exala suas contradições e desigualdades. Porém, isso só pode acontecer se a comunidade estiver consciente da necessidade solidária e colaborativa durante as atividades. Assim, para que os processos de Economia Solidária não se percam, é fundamental enxerga-la para além de uma política pública de governo, mas como um novo formato de produtividade e, ao mesmo tempo, luta social constante.

A solidariedade na economia não pode ser vista como uma condição de precarização da vida das pessoas, mas uma forma de emancipação de melhoria de vida. Para isso é importante que tenha um reconhecimento e apoio institucional dentro da estrutura coletiva e cooperativa. Além disso, é necessário que parte dos recursos públicos sejam destinados especificamente a política pública de Economia Solidária, por isso os planos plurianuais, e as leis orçamentárias precisam prover rubricas específicas para a produção e as relações solidárias, além de reservar fundos públicos ou possibilidades semelhantes.

\section{Referências}

ABRAMOVAY, Ricardo. Funções e medidas da ruralidade no desenvolvimento contemporâneo. Rio de Janeiro: IPEA, 2000.

BRASIL. Companhia de Pesquisa de Recursos Minerais (CPRM). Projeto cadastro da infra-estrutura hídrica do Nordeste: diagnóstico do munícipio de Salgado/Sergipe. Brasília, 2002. Disponível em: http://www.cprm.gov.br/publique/media/hidrologia/mapas_publicacoes/cadastro_infrae strutura_sergipe/Salgado.pdf . Acesso em: 29 de mai. 2019.

BRASIL. Instituto Brasileiro de Economia (IBRE). Monitor do PIB-FGV: indicador mensal de dezembro de 2018. Brasília, 2019. Disponível em: https://portalibre.fgv.br/data/files/93/25/6E/93/F5509610E87B8B868904CBA8/Monitor \%20do\%20PIB-FGV\%20-\%20Fevereiro\%20de\%202019\%20\%20Ref.\%20de\%20dezembro.pdf Acesso em: 03 de jun. 2019.

BRASIL. Instituto Brasileiro de Geografia e Estatística (IBGE). Panorama Municipal: Salgado/Sergipe. Brasília, 2018. Disponível em:

http://cidades.ibge.gov.br/brasil/se/salgado/panorama Acesso em: 03 de jun. 2019.

BRASIL. Instituto Humanitas Unisinos (IHU). Redução do PAA contribui para desmonte da agricultura familiar. Rio Grande do Sul, 2017. Disponível em: < http://www.ihu.unisinos.br/78-noticias/570214-reducao-no-paa-contribui-paradesmonte-da-agricultura-familiar> Acesso em: 03 de jun. 2019. 
Daniela Santos FEITOZA, D. S.; COSTA, J. E. da; PINHEIRO, F. dos S.

BRASIL. Portal Cirandas. Campanha Permanente Contra Agrotóxicos e pela vida. Brasília, 2011. Disponível em: http://cirandas.net/leidaecosol/campanha-permanentecontra-agrotoxicos-e-pela-vida Acesso em: 29 de mai. 2019.

BRASIL. Senado Federal. Proposta de Emenda à Constituição ${ }^{\circ}$ 55: $\mathrm{PEC}$ do teto dos gastos públicos. Brasília, 2016. Disponível em: <

https://www25.senado.leg.br/web/atividade/materias/-/materia/127337> Acesso em: 29 de mai. 2019.

CORRÊA, Roberto L. Redes Geográficas: reflexões sobre um tema persistente. Revista Cidades, São Paulo. v. 9, n. 16, 2012.

CARVALHO, Diana M.; et al. Aspectos do mundo rural e do desenvolvimento territorial do Nordeste. São Cristóvão: Editora UFS, 2019.

CHESNAIS, François. A mundialização do capital. São Paulo: Xamã, 1996.

ENTREVISTA. Aplicação de questionário e entrevista semiestrutura para associadas da Mini Fábrica de Doces do povoado Tombo. Salgado/SE, 2019.

GODOY, Tatiane M. P. O espaço da Economia Solidária: a autogestão na reprodução das relações sociais e os limites da emancipação social. Tese (doutorado) - Universidade Estadual Paulista, Instituto de Geociências e Ciências Exatas. Rio Claro/SP, 2009.

GRISA, Cátia; SCHNEIDER, Sérgio. Três Gerações de Políticas Públicas para a Agricultura Familiar e Formas de Interação entre Sociedade e Estado no Brasil. Revista Economia e Sociologia Rural, Piracicaba-SP, vol. 52, supl. 1, 2014.

GUERRA, Alexandre; et al. Brasil 2016: Recessão e golpe. São Paulo: Fundação Perseu Abramo, 2016.

HARVEY, David. A produção capitalista do espaço. São Paulo: Editora Annablume, 2005.

MARCONI, Marina de A.; LAKATOS, Eva M. Fundamentos de metodologia científica. $5^{\circ}$ ed. São Paulo: Atlas, 2003.

MARX, Karl. O Capital: crítica da economia política. (livros 1 e 2). Rio de Janeiro: Editora Civilização Brasileira, 2005.

MONTEIRO, Alcides A.; MONTEZ, Mário M. Sentidos de mobilização e de desmobilização da ação coletiva. Revista Opinião Pública, Campinas, vol. 21, no 1 , abril, 2015.

OLIVEIRA, Maria A. S. Entrevista (maio de 2019): arquivos em MP3. Entrevistador: Daniela Santos Feitoza e Fabiana dos Santos Pinheiro. Salgado/SE, 2019.

ORTIGOZA, Silvia A. G. O papel do Território nos desafios da organização e consolidação das redes solidárias. I Congresso de Pesquisadores da Economia

Solidária (CONPES). São Paulo: UFSCar, 2015. 

Daniela Santos FEITOZA, D. S.; COSTA, J. E. da; PINHEIRO, F. dos S.

SANTOS, M. A natureza do espaço: Técnica e tempo. Razão e emoção. $2^{\text {a }}$. ed. São Paulo: Hucitec, 1997.

SCHNEIDER, Sérgio. Teoria social, agricultura familiar e pluriatividade. Revista Brasileira de Ciências Sociais, São Paulo, v. 18, n.51, p. 99-121, 2003.

SERGIPE. Governo de Sergipe. Feira da agricultura familiar chega ao município de Salgado. Sergipe, 2015. Disponível em: http://se.gov.br/noticias/inclusao-social/feirada-agricultura-familiar-chega-ao-municipio-de-salgado Acesso em: 29 de jun. 2019.

SERGIPE. Governo de Sergipe. Jackson entrega fábrica de doces, autoriza pavimentação e inaugura clínica em Salgado. Sergipe, 2014. Disponível em: http://www.agencia.se.gov.br/noticias/governo/jackson-entrega-fabrica-de-docesautoriza-pavimentacao-e-inaugura-clinica-em-salgado Acesso em: 09 de jun. 2019.

SINGER, Paul. Introdução à Economia Solidária. São Paulo: Fundação Perseu Abramo, 2002.

SIQUEIRA, Edmar R. O território rural centro-sul de Sergipe. Aracaju: Empresa Brasileira de Pesquisa Agropecuária (EMBRAPA)- Tabuleiros Costeiros, 2010.

SMITH, Neil. Desenvolvimento desigual: natureza, capital e a produção do espaço. Rio de Janeiro: Bertrand Brasil, 1988.

SOUZA, Marcelo Lopes de. Os conceitos fundamentais da pesquisa socioespacial. Rio de Janeiro: Editora Bertrand, 2016.

TEIXEIRA, Elenaldo C. O papel das políticas públicas no desenvolvimento local e na transformação da realidade. Associação de Advogados de Trabalhadores Rurais no Estado da Bahia (AATR-BA), 2002.

TORRE, André. Desenvolvimento local e relações de proximidade: conceitos e questões. Revista Internacional de Desenvolvimento Local. Vol. 4, N. 7, p. 27-39, Set. 2003.

VASCONCELOS, Maria C. A. Além da geração de trabalho e renda: Economia Solidária e participação de cooperados/associados em Sergipe. Tese (Doutorado) Pontifícia Universidade Católica de São Paulo (PUC/SP). São Paulo, 2007. 